\title{
Simulation of Harmful Fuel Inflamer through Outlet \& Maximum Pressure in Cylinder with Temperature in Engine of Vehicles \\ Run Xu
}

Department of Metallurgical Engineering, Gyeongsang National University, Chinju 52828, Korea

\author{
DOI: $\underline{10.36348 / \text { sjet.2020.v05i10.008 }}$ \\ | Received: 06.10.2020 | Accepted: 21.10.2020 | Published: 30.10.2020 \\ *Corresponding author: Run Xu
}

\section{Abstract}

The toxic fuel is harmful to human health and environment in earth, so that simulation is studied to find the relation of inflamer and time and temperature in Engine is important now. $\mathrm{CO}$ and NO is searched with the mass ratio and find the $\mathrm{NO}$ is bigger than $\mathrm{CO}$ under certain time. Meantime the more value of them contains the more emitted gas will be with the consuming of 7.6 iit/h. The $\mathrm{CO}$ and $\mathrm{NO}$ will incline when their concentration incline from $0.2 \%$ to $4 \%$. $\mathrm{CO}$ with the engine internal diameter being $87 \mathrm{~mm}$ is higher than its $75 \mathrm{~mm}$. The big one has higher value than the small one. With the increasing temperature the inflamer is high, the temperature is big since the power is big too. It is found that $\mathrm{x}$ which is times of RT (room temperature) pressure increases when the temperature increases. Meantime it increases when cylinder length decreases.

Keywords: Toxic inflamer; simulation; $\mathrm{CO} \& \mathrm{NO}$; internal diameter; temperature.

Copyright ( $) 2020$ The Author(s): This is an open-access article distributed under the terms of the Creative Commons Attribution 4.0 International License (CC BY-NC 4.0) which permits unrestricted use, distribution, and reproduction in any medium for non-commercial use provided the original author and source are credited.

\section{INTRODUCTION}

The toxic fuel is harmful to human health and environment in earth, so that simulation is studied to find the relation of inflamer and time and temperature in Engine is important now. Among them $\mathrm{CO} \& \mathrm{NO}$ is toxic inflamer which is studied to look for the internal relation in vehicles [1-4]. Through calculation the temperature of outlet in engine is successful so we can simulate it through engine cylinder. Meantime the specified $\mathrm{CO} \& \mathrm{NO}$ is studied to find the quantity of toxic fuel. The temperature may attain several hundred ${ }^{\circ} \mathrm{C}$ is studied in this paper details. In order to search these respects this paper is simulated and investigated. They are harmful after they are melt in our blood. It can result in many disease in our bodies. Meantime it has harm to environment. To be benefit to us the minimum toxic gas may be outlet with many vehicles. It is evaluated that one family has a vehicle ie. mainly car in every three families in China. There are about three millions cars in Beijing city. So they are huge discharged gas specially CO and NOx. In this paper we discuss these two toxic fuels detail to search their discharged gas quantity. We look for this minimum gas method for environment and health, which is destination.
The parameter of inflamer force is important at engine cylinder of vehicle. $\mathrm{x}$ which is times of $\mathrm{RT}$ (room temperature) pressure is named this constant. It is investigated that it is variable with temperature and cylinder length. It has significant role in structuring engine inner cylinder simulation and practical parameters. It is to evaluate the inflamer quantity and velocity from cylinder which includes $\mathrm{CO}$ and NOx etc harmful gas. It is convenient for us to control the inflamer and done the prediction and simulate status regardless of experimental measure. It must connect with these measure later to check its precision to be proven its correction.

Modeling toxic fuel

According to gas principle formula

$\mathrm{n} R d T=P d V$

It has $d F V / s=n R d T$

so $V=n R d T S / d F$

According to (1)

$F=n R d T S / d V$

Supposes $F=x m g$ 
Here, $\mathrm{n}$ is moles; $\mathrm{T}$ is temperature $\mathrm{K}$; $\mathrm{R}$ is 8.3 $\mathrm{J} /(\mathrm{mol.K}) ; \mathrm{F}$ is force $\mathrm{N} ; \mathrm{S}$ is square of engine inner square, $\mathrm{m}^{2}, \pi d_{0}^{2} / 4 ; \mathrm{d}_{0}$ is engine diameter $\mathrm{m}$; $\mathrm{V}$ is volume of gas in engine.

\section{DISCUSSION}

As in Figure $1(\mathrm{a}, \mathrm{b}) \mathrm{CO}$ and $\mathrm{NO}$ is searched to the mass ratio with emitted $2 \%$ and find the $\mathrm{NO}$ is more than $\mathrm{CO}$ under certain time with the consuming of 7.6lit/h. Meantime the more value of them contains the more emitted gas will be. The $\mathrm{CO}$ and $\mathrm{NO}$ will incline when their concentration incline from $0.2 \%$ to $4 \%$. In Figure $2(\mathrm{a}, \mathrm{b})$ the $\mathrm{CO}$ with the engine internal diameter being $87 \mathrm{~mm}$ is more than its $75 \mathrm{~mm}$. With the increasing temperature the inflamer is high, the temperature being big since the speed is big too. It is under $2 \%$ concentration of toxic fuel and at the speed of $30 \mathrm{Km} / \mathrm{h}$.

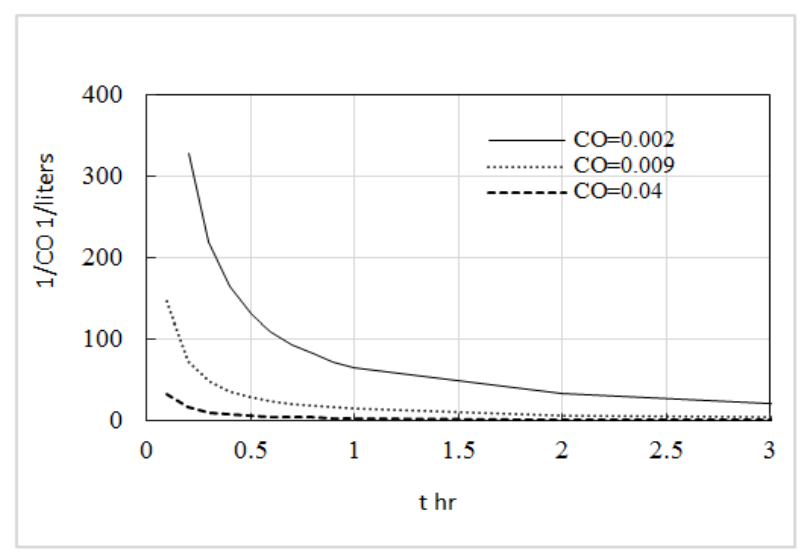

(a) $\mathrm{CO}$

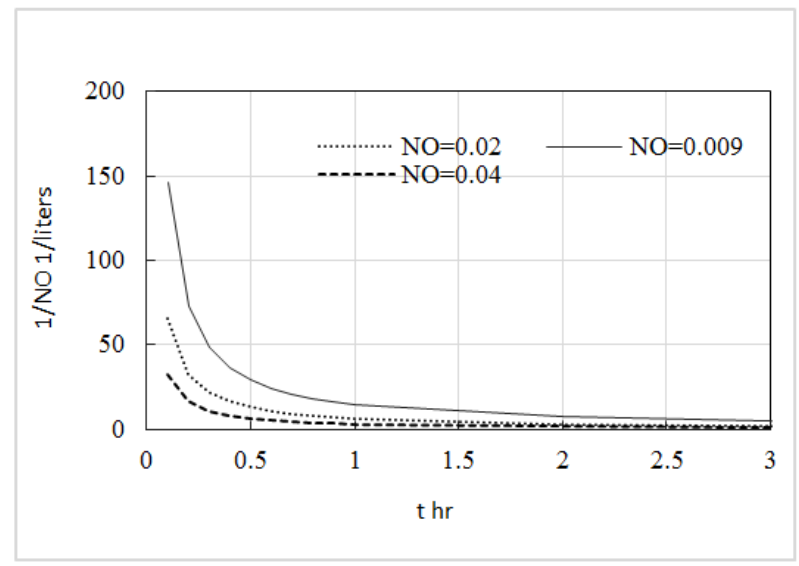

(b) NO

Fig-1: Curves of emitting CO\&NO and time with 7.6lit/h

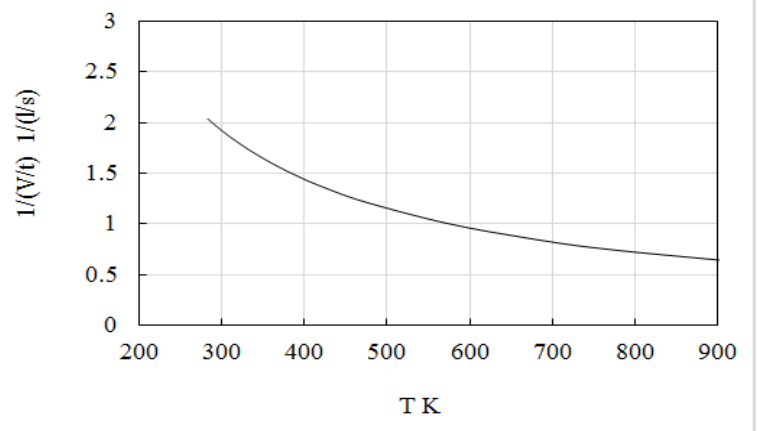

(a) $\mathrm{d}=75 \mathrm{~mm}$

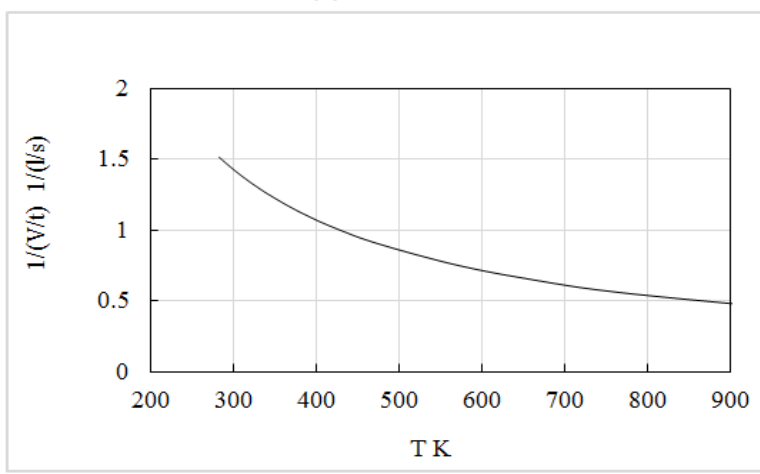

(b) $\mathrm{d}=87 \mathrm{~mm}$

Fig-2: Curve of $\mathrm{NO}_{2}$ and time with variable inner diameter and stable $v=30 \mathrm{Km} / \mathrm{h}$ under $0.1 \%$ concentration

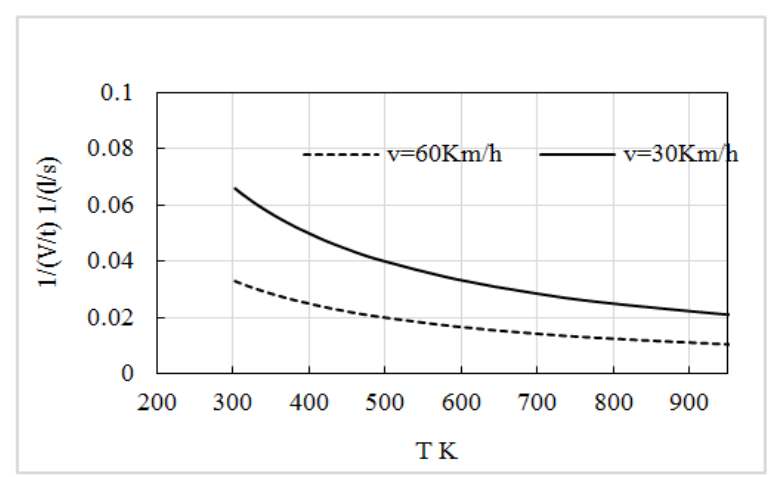

(a) $\mathrm{d}=75 \mathrm{~mm}$

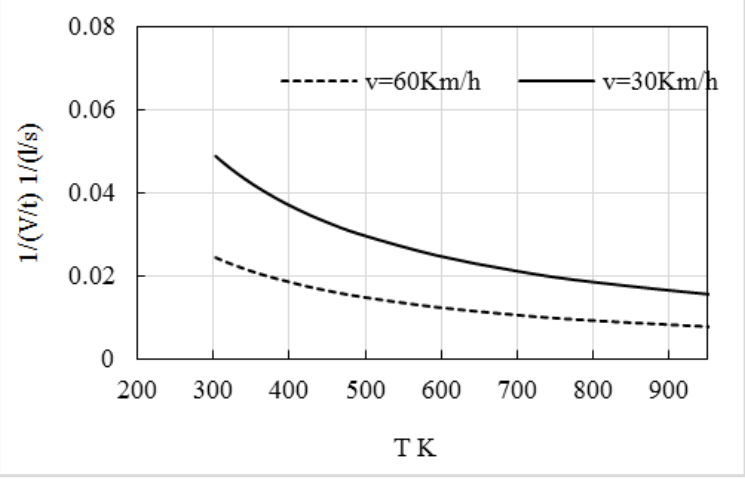

(b) $\mathrm{d}=87 \mathrm{~mm}$

Fig-3: Curve of NO and time with inner $d$ and variable velocity under $2 \%$ concentration 
The research scope of temperature is from room temperature to $650^{\circ} \mathrm{C}$. Here it is found that the toxic fuel is increased with the increasing temperature - It is due to the high speed of vehicles. It expresses that the high temperature is attained here in this study. The course of outlet of fuel is necessary so the outlet in pipe is lower than here outlet interface.so the temperature in here is higher than $527^{\circ} \mathrm{C}$. As to the definite interface $1 / \mathrm{V}$ we know it can not be clarified. But if $0.12 \mathrm{ml} / \mathrm{s}$ or above is interface, it is known to be how much. In Figure $2(\mathrm{a}, \mathrm{b})$ the toxic gas $1 / \mathrm{NO}_{2}$ decreases when temperature inclines at condition of $0.1 \% \mathrm{NO}_{2}$ concentration. If the engine cylinder inner diameter is $75 \mathrm{~mm}$ the data is as Figure 2(a). Meantime if $\mathrm{D}$ is $87 \mathrm{~mm}$ it is as Figure 2(b). The quantity is larger in $\mathrm{NO}$ than that in $\mathrm{NO}_{2}$. As Figure 3(a,b) the toxic gas NO is emitted when vehicle speed is $60 \mathrm{Km} / \mathrm{h}$ and $30 \mathrm{Km} / \mathrm{h}$ at condition of $2 \% \mathrm{NO}$ concentration. It is found that it is bigger at $60 \mathrm{Km} / \mathrm{h}$ than that at $30 \mathrm{Km} / \mathrm{h}$ and it is bigger at $\mathrm{d}$ being $87 \mathrm{~mm}$ than $75 \mathrm{~mm}$.

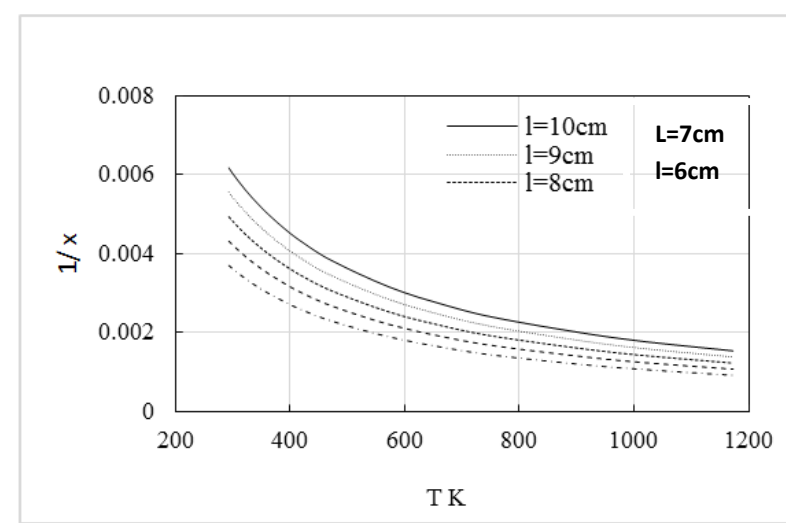

Fig-4: The relationship of $1 / x$ and temperature with variable length in engine cylinder

It is found from Figure-4 that $\mathrm{x}$ which is times of RT pressure increases when the temperature increases. Meantime it increases when cylinder length decreases. It is status that the cylinder volume is maximum so the times are from several hundreds to bigger one to compare with atmosphere. In this study it is proposed that it is emitting atmosphere whose volume is very much to compare the seal cylinder which is the biggest volume and temperature in cylinder. It is convenient to study in model to evaluate the emitting course from the biggest engine work end to inflamer through vent pipe because the measure is very difficult to adopt data.

\section{CONCLUSIONS}

$\mathrm{CO}$ and NO is searched with the mass ratio and find the $\mathrm{NO}$ is more than $\mathrm{CO}$ under certain time. $\mathrm{CO}$ with the engine internal diameter being $87 \mathrm{~mm}$ is more than its $75 \mathrm{~mm}$. With the increasing temperature the inflamer is high, the temperature is big since the force is big too. it is found that it is bigger at $60 \mathrm{Km} / \mathrm{h}$ than that at $30 \mathrm{Km} / \mathrm{h}$ and it is bigger at $\mathrm{d}$ being $87 \mathrm{~mm}$ than $75 \mathrm{~mm}$. The $\mathrm{CO}$ and NO will incline when their concentration incline from $0.2 \%$ to $4 \%$. It is found that $\mathrm{x}$ which is times of room temperature pressure increases when the temperature increases. Meantime it increases when cylinder length decreases.

\section{REFERENCES}

1. Wu, J. (2015). Auto Engine Principle [M], China Machine Press. 2012:175.

2. $\mathrm{Pu}$ Lianggui, Chen Guoding, $\mathrm{Wu}$ Liyan. Mechanical Design [M], Advanced Education Publisher. 24, 30.

3. Peng, W. S., Li, Z. M., \& Huang, H. 1. (2008). Mechanical Design [M], Advanced Education Publisher. 195-196.

4. $\mathrm{Xu}, \mathrm{L}$. (2017). Numerical prediction and support system of safety service life of remanufactured impeller considering damage fuzziness [D]. Chongqing University. 